\title{
A Study on the Translation of "Red Sorghum Family" from the Perspective of Three-Dimensional Transformation of Eco-Translatology
}

\author{
Fei Liu \\ School of Foreign Languages, Shanxi Datong University, Datong, China \\ Email: feiexertion@163.com
}

How to cite this paper: Liu, F. (2021). A Study on the Translation of "Red Sorghum Family" from the Perspective of ThreeDimensional Transformation of Eco-Translatology. Open Journal of Social Sciences, 9, 25-31.

https://doi.org/10.4236/jss.2021.96003

Received: May 6, 2021

Accepted: June 4, 2021

Published: June 7, 2021

Copyright $\odot 2021$ by author(s) and Scientific Research Publishing Inc. This work is licensed under the Creative Commons Attribution International License (CC BY 4.0).

http://creativecommons.org/licenses/by/4.0/

(c) (i) Open Access

\begin{abstract}
Red Sorghum Family is one of Mo Yan's representative works and the first English translation of Mo Yan's works by Howard Goldblatt. The ecological environment of translation restricts and influences the translator's choice of translation strategies, methods and techniques in the process of translation. According to the eco-translatology, translation is a transformation from language dimension, culture dimension and communication dimension. This paper analyzes the three-dimensional transformation between the source language and the target language in the English version of Red Sorghum Family, and holds that a good translation must be the translator's effective adaptation to the ecological environment including the source language, the source culture and the target language.
\end{abstract}

\section{Keywords}

Eco-Translatology, Three-Dimensional Transformation, Red Sorghum Family

\section{Introduction}

Red Sorghum Family is one of Mo Yan's representative works and the first English translation of Mo Yan by Howard Goldblatt, who is a famous American Sinologist and recognized as the chief translator of modern and contemporary Chinese literature. Since its publication, the English version of Red Sorghum Family has aroused great repercussions in the literary world at home and abroad. The success of Howard Goldblatt's English translation of Red Sorghum Family lies not only in the translator's understanding and acceptance of tradi- 
tional Chinese culture, but also in his deep understanding of the historical background and writing background of the original story (Hao, 2019).

Eco-translatology (also ecological translation theory) is an interdisciplinary theory based on Darwin's natural selection theory. It explains the process of translation through adaptation and selection, which emphasizes on the "translator centered" concept. The translation ecological environment here refers to "the world presented by the source text and the source language, that is, the whole of language, communication, culture and society, as well as the mutual connection and interaction among the author, readers and customers" (Hong \& Cao, 2020). The ecological environment of translation restricts and influences the translator's choice of translation strategies, methods and techniques in the process of translation, which is the premise and basis of the translator's multi-dimensional adaptive selection and transformation (Geng, 2020).

\section{Ecological Translatology}

Eco-translatology was first proposed by Professor Hu Gengshen, a domestic scholar at the beginning of the new century. Eco-translatology is based on Darwin's "adaptive selection theory" and the oriental wisdom of "harmony between man and nature", and holds that translators' translation activities are always in the translation ecological environment, and translation is "the translator's selective activity to adapt to the translation ecological environment" ( $\mathrm{Hu}, 2008)$. As an ecological paradigm of translation studies, eco-translatology focuses on "the interaction between the translator's subject and other subjects in translation practice and the influence of the overall environment on the translator and the translated version" (Cao \& Li, 2020). Therefore, translators need to make multi-dimensional adaptive selections and transformation between the source language and the target language on the basis of adapting to the ecological translation environment. It mainly includes the translator's adaptive choice transformation in linguistic dimension, cultural dimension and communicative dimension.

\section{On "Three-Dimensional Transformation" in Eco-Translatology}

According to eco-translation theory, in the process of translation, three key dimensions must be transformed, namely "three-dimensional transformation".

1) Transformation in language dimension

In fact, it is to realize the corresponding transformation between different language forms. Faithfulness is a principle and premise in translation, not only for the contents and information carried by the sour language, but also for the language form. The translator has to try to keep the target language in conformity with the source language.

2) Transformation in culture dimension

In the process of translation, readers should comprehensively consider the 
cultural background of the society in which the language is located. After all, language and culture are closely linked, and each language has its own unique cultural connotation. Therefore, translation is not only the translation of language, but also the culture behind it, otherwise it is superficial and may violate the criterion of expressiveness proposed by Yan Fu.

3) Transformation in communication dimension

In the process of translation, translators should pay attention to the specific environment in which language is used. The same words, when used in different environments, may have different meanings, even opposite meanings. Therefore, translators must pay attention to the context in which they are used in the process of translation, and make targeted adaptive selection and transformation of bilingual communicative intentions.

Eco-translatology, as an interdisciplinary approach to ecological translation research, is an ecological paradigm and research field in which translation is adaptation and selection, which is a comprehensive study of translation from an ecological perspective.

\section{Three-Dimensional Transformation Strategy in Red Sorghum Family under Ecological Translatology}

\subsection{Transformation in Language Dimension}

Translation is a dynamic process of translators' multi-dimensional adaptation and adaptive selection. From the perspective of eco-translatology, transformation in language dimension is a process in which translators choose from vocabulary, sentence patterns and other language forms and adapt to the ecological translation environment. Because different languages have great differences in language style, grammar system and vocabulary selection, it is not easy to complete the conversion between two languages (Zheng, 2020). Translators should choose vocabulary and sentence patterns to adapt to the ecological environment of translation, so as to reproduce the language features and charm of the original works. Such as:

Example 1: “烧得她! 烧得她不轻, 她打的什么谱?”

"She's spoiled, spoiled rotten! Who does she think she is?" (Zhang, 2019a)

“烧”、“打……谱” are dialect vocabulary, which refer to “I don't know happiness when I am in it" and "I secretly plan and plan in my heart". From the perspective of context, this example expresses the blame and helplessness of "great grandfather" for "Jiu-Er". Howard Goldblatt accurately understood the inherent meaning of this dialect, and then translated it into the standard language "spoiled rotten!" on the basis of respecting the original text "Who does she think she is?". In this way, not only the tone of speech and emotional expression of the characters in the original text are reproduced, but also the stubborn and independent personality characteristics of "great-grandfather" and "Jiu-Er" are vividly displayed, so that the target language readers have a deeper understanding of the characters in the novel. 
Example 2: 余占鳌平静地对着吃拤饼的人走, 他前进一步, 吃拤饼者就缩 一点。吃拤饼的人眼里跳出绿火花, 一行行雪白的清明汗珠从他脸上惊惶地 流出来。(Zhang, 2019b)

Yu Zhan'ao walked calmly up to the man, who began backing up. Green flames seemed to shoot from his eyes, and crystalline bead of sweat scurried down his terrified face.

Unconventional color words play a very important role in Red Sorghum Family. The author creates magical scenes, portrays characters and expresses subjective emotions through unconventional color words. Unconventional color words mean that the use of color words does not conform to logical habits, but describes colors according to the translator's subjective and perceptual feelings.

For example, the author describes sparks as green, which is different from people's original cognition. Both the target language and the source language have the same cognition of green, and they are used to express frightened color images. The translator uses semantic translation to translate literally, conveying the magic scene created by the color words of the source text, restoring the color environment depicted by the source text, and unifying the source text, the target text and the translator.

It can be seen from the above example that Howard Goldblatt not only pays attention to the transmission of the meaning of color words and the symmetry of language structure, but also makes up for the coherence and logic in Chinese parataxis, and pays more attention to maintaining the language style of the source text and creating magical scenes, which makes Mo Yan's novels understood and accepted by the Westerners.

\subsection{Transformation in Culture Dimension}

The transformation in culture dimension means that translators pay attention to the cultural differences between the source language and the target language, and avoid the misunderstanding of the target language readers. Therefore, translators need to adapt and choose appropriately in different cultures (Jin, 2019).

Although Howard Goldblatt has lived in China for many years and has rich cultural heritage and outstanding Chinese talent, there are great differences between English and Chinese in ways of thinking, religious beliefs, political culture, social culture and values. In translation activities, as a translator, Howard Goldblatt should be faithful to the original text and meet the cultural background requirements of the target readers. Therefore, domestication and foreignization are used in translation activities. In the English version of Red Sorghum Family, "flexibility" is adopted when dealing with the contents related to religious culture and political culture, which makes it closer to the cultural needs of the target language.

Example 3: 天籁之音。

Sound of the woodwinds. 
“天籁” is the voice from the sky, and “天籁之音” describes it as sweet. From the perspective of eco-translatology, the translator has not alienated it into "sound of sky" or "sound of heaven". Instead, he chose a domesticated translation, using "woodwinds" to describe the sound of the sound, avoiding readers' incomprehension, and also conveying the meaning of "pleasant sound".

The author collected 56 names/places appearing in the first two chapters of Red Sorghum Family. By comparing the translated versions, the author finds that Howard Goldblatt has adopted six translation strategies, as shown in Figure 1 .

It can be seen from the above figure that "transliteration + literal translation" accounts for the largest proportion, exceeding 1/3. "Transliteration", "literal translation" and "free translation" account for the same proportion. The translation strategies of "transliteration + free translation" and "transliteration + annotation" are seldom used.

The names/places in Red Sorghum Family contain rich cultural information, so it is not easy to express all their cultural connotations in translation. Howard Goldblatt adaptively chooses different translation strategies, and makes the translation as concise and easy to understand as possible on the basis of preserving cultural information, thus completing the adaptation and selection in cultural dimension, for instance, “恋儿” (Passion) is translated freely; “鲁班” (master carpenter Lu Ban) is added with the explaination of his identity.

\subsection{Transformation in Communication Dimension}

The translator's transformation in communication dimension is an adaptive choice based on bilingual communicative intention in translation activities. In order to meet the reading needs and expectations of target readers, the translator, as a senior Sinology researcher and translator, translates the language-loaded words in his works according to their meanings, so as to meet the purpose of communication.

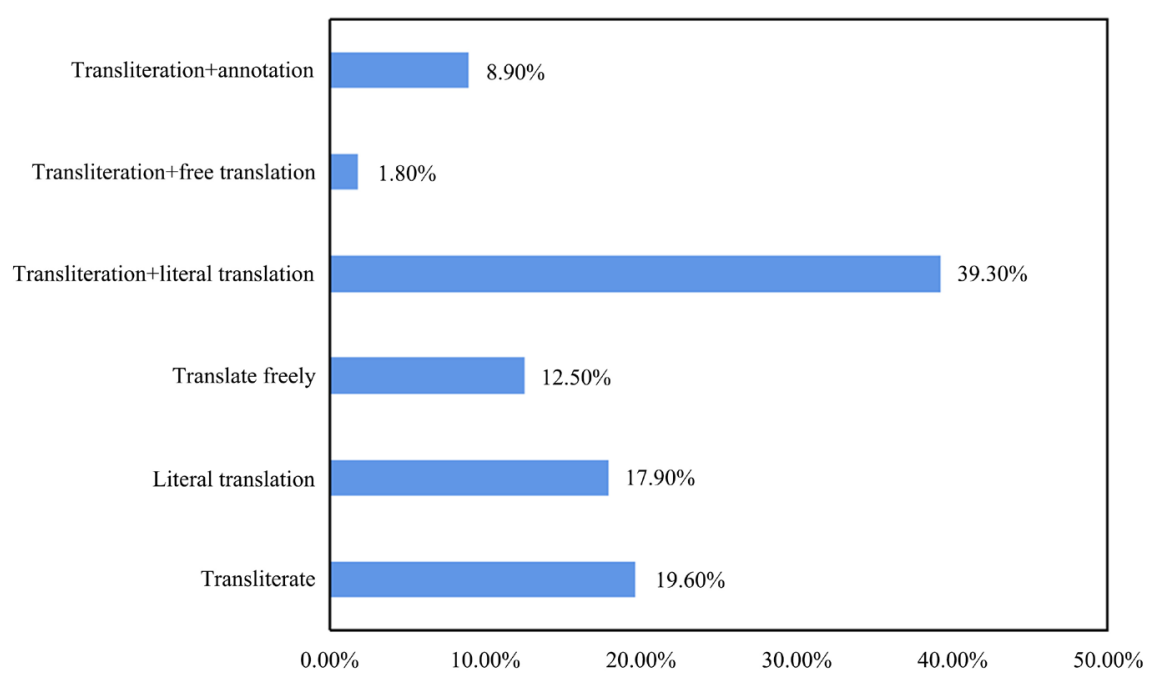

Figure 1. Proportion of translation strategies of names/places. 
From the perspective of eco-translatology, the adaptive choice in the communicative dimension is that translators pay attention to the communicative function of bilingualism in the process of translation. In this dimension, apart from the transmission of language and culture, the translator puts emphasis on the transmission of communicative intention, so that readers of different languages and cultures can communicate with each other by means of translation, so that the communicative intention can be reflected in the target text and the communication of culture can be promoted. Thus, realize the communicative intention. That is to say, the translator has chosen a translation strategy suitable for the target language readers, and the translation conforms to the reading habits of the target language readers, serves the target language readers, and truly realizes the purpose of "doing something in translation".

Example 4: 一群群大雁往南飞, 一会儿排成个 “一”字, 一会儿排成个 “人”字。

Wild geese flew through the sky heading south, their formation changing from a straight line on minute to a $\mathrm{V}$ the next.

The original text uses Chinese characters “一” and “人” to describe the formation of the geese flying south. However, English readers do not understand Chinese. If they are directly translated into the corresponding English "one" and "people", it will inevitably cause readers' misunderstanding and the communicative intention cannot be achieved. Then the translator translated it into "a straight line", "V" shape, so that the target language readers can intuitively understand the formation of the geese flying south according to their own cultural background.

Example 5: 为了安慰被惊动的鬼魂, 母亲在坟墓前, 烧了一刀黄表纸。

In order to calm the frightened souls of the dead. Mother burned a stack of yellow spirit money at the head of the grave.

“黄表纸” is a unique cultural image in China, which is often used to worship gods or sacrifice. If the translator chooses to use "yellow paper" only from the language dimension or from the culture dimension, he can't convey the image of “gold” or “money” represented by the sacrificial “黄表纸” here.

In Chinese traditional culture, “烧黄表纸” is to give money to the dead to comfort the dead. Considering that the target readers have difficulty in understanding the cultural image of “黄表纸”, according to the principle of communicative dimension, the translator analyzes the best relevance between the original information and context in translation, and chooses the best relevance to meet the readers' cognitive ability and expectation. The translator chooses communicative translation strategies, makes transformational choices, interprets the source text, and removes the reading barrier of the target readers.

\section{Summary}

Eco-translatology theory provides strong support for translators to adapt to the whole translation ecosystem from multiple angles and levels. Based on the 
theory, this paper makes a comprehensive study of the English version of Red Sorghum Family from three dimensions: language dimension, culture dimension and communication dimension. In the English version of Red Sorghum Family, Howard Goldblatt, the translator, shows great initiative and creativity in the transformation from the three dimensions. Or literal translation or free translation, or additional translation or modified translation, all fully reflect the translator Howard Goldblatt's thorough grasp of the original works. With the use of various translation techniques, the target language readers can have a deeper understanding of the true connotation of this novel.

\section{Acknowledgements}

This research was supported by Youth Scientific Research Project of Shanxi Datong University (Project No. 2019Q8).

\section{Conflicts of Interest}

The author declares no conflicts of interest regarding the publication of this paper.

\section{References}

Cao, Y. \& Li, Y. (2020). Interpretation of Culture-Loaded Words from the Perspective of Eco-Translatology-Based on Translator's Adaptation and Choice. Youth, No. 4, 17-18.

Geng, J. (2020). Three-Dimensional Transformation of Public Signs from the Perspective of Eco-Translatology. Journal of Cultural Studies, No. 3, 187-189.

Hao, T. (2019). Howard Goldblatt's Translation Studies from the Perspective of Cultural Turn -Taking "Red Sorghum" as an Example. Northern Lights, 257, 91-92.

Hong, J., \& Cao, K. (2020). Three-Dimensional Transformation of Chemical English Text Translation from the Perspective of Eco-Translatology. Journal of Jiamusi Institute of Education, 36, 139-140.

Hu, G. (2008). Interpretation of Eco-Translatology. Chinese Translation, No. 6, 11-15.

Jin, D. (2019). A Study on Translator's Role in English Translation of University Charter Based on Eco-Translatology. Journal of Zhejiang Jiaotong Vocational and Technical College, 20, 55-58.

Zhang, G. (2019a). A Case Study of Howard Goldblatt's English Version of "Red Sorghum Family"-Based on the Ideological Perspective of Rewriting Theory. Campus English, No. 3, 238-238.

Zhang, J. (2019b). Research on the Culture, Translation and Publicity of Geographical Names-From the Perspective of Eco-Translatology. Think Tank Times, No. 30, 235-236.

Zheng, S. (2020). English Translation of Chinese Culture-Loaded Words Based on Eco-Translatology Theory. Mass Standardization, No. 23, 160-161. 